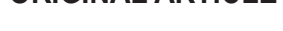

\section{Study on Secondary Cable Adjustment for Cable-stayed Bridges Without back Cables}

\author{
Zengshou Sun, Xiaocong Liu, Jianfeng Ma \\ School of Civil Engineering, Zhengzhou University, Zhengzhou City, Henan Province
}

Abstract: The structure of cable-stayed bridge without back cable is a new breakthrough.In this paper, the cable adjustment process of linzhou yingbin bridge is studied. the whole bridge model is established using the finite element software MIDAS CIVIL. This paper compares the measured cable force with the designed cable force and gets range of cable force difference, The influence matrix method is used for the second cable adjustment to ensure that the stress and structural deformation in the process of cable adjustment are within the range of the design requirements. The cable force variation of the whole bridge is detected by dynamic measuring instrument to ensure the construction safety in the process of cable adjustment.

Keywords: Backless Cable-stayed Bridge; the Adjustment of Cable Force; Analytical investigation; Influence Matrix Method

\section{Introduction}

Conventional cable-stayed bridges have cables on both sides of the pylon, and the horizontal force of cables on both sides of the pylon can keep the structure flat under dead load. Balance, the main tower only bears certain horizontal force and bending moment under the action of live load and additional load. Unlike conventional cablestayed bridges, there is no back cable-stayed bridges rely on high-rise inclined pylons to support slender bridge girders, and inclined main pylons and main girders are connected by unilateral stay cables. The beams are connected together to form a consolidated balance system of the beam tower pier, ensuring the stability of the structure and fully embodying mechanics and aesthetics.

The perfect combination of ${ }^{[1]}$ as a cable system of flexible structure, the cable force value in the bridge stage not only affects the internal force and line of the main girder. Its shape, but also affects the alignment and internal force of the inclined tower, so it is necessary to establish and ensure a reasonable cable force for the completed bridge ${ }^{[2]}$. In the process of cable tension for cable-stayed bridges without back cables, batch tension is often used, and cable tension in the later period will inevitably lead to damage to the cable. Changes in cable forces of tension cables. Therefore, the finite element software is usually used before construction, and the unknown load system is used according to the cable force value of the completed bridge. The number method ${ }^{[3]}$ carries out cable force iteration to determine the initial tension value of each cable in the initial tension. Due to temporary load, temperature due to the influence of various factors such as degree, the measured cable force at the completion stage will have certain errors with the designed cable force. In order to ensure the rationality of the structural stress, secondary cable adjustment is required to ensure that the cable force error value is within the required range ${ }^{[4]}$. No back involved in this article. The internal forces and alignment of the main girder and tower before and after cable adjustment of cable-stayed bridge are within the design requirements, and the cable adjustment in a small range will adjust the bridge.

The change of internal force has little effect, so this article will not study it. The cable length of cable-stayed bridge

Copyright (C) 2020 Zengshou Sun et al.

doi:10.18282/ice.2020.313

This is an open-access article distributed under the terms of the Creative Commons Attribution Non-Commercial License (http://creativecommons. org/licenses/by-nc/4.0/), which permits unrestricted non-commercial use, distribution, and reproduction in any medium, provided the original work is properly cited. 
without back cable is relatively short, and the influence of cable gravity on cable force is within $1 \%$, with the maximum sag accounting for cable. The cable length shall not exceed $0.5 \%$,so the sag effect ${ }^{[5]}$ may not be considered. According to the combination of theoretical analysis and practice, in the existing secondary cable adjustment. Among the methods, the iterative method and the influence matrix method are relatively practical. In this paper, the influence matrix method is mainly considered. The influence matrix method uses the finite element carries out static analysis on the results, obtains an influence matrix conforming to the linear superposition theory, and applies different force to each stay cable in the model. The unit cable force is added to calculate the cable force variation of other cables, and the influence matrix of cable force is obtained by using normalization principle. Although the response matrix method cannot consider the nonlinearity of the structure, it can reasonably select some cables to adjust according to the cable force difference value. After adjustment, the cable force of the whole bridge can be within the design range, greatly reducing the workload.

\section{Impact matrix method}

For cable-stayed bridges without back cables constructed with full bore supports, the forces of the main tower and the tension cables are constructed in stages and the cable forces are determined after the supports are removed. The transformation will directly disturb the internal force and deformation of the beam. Therefore, at the end of the secondary pavement of the bridge, the permanent load is applied. After finishing, the cable force value of the whole bridge is measured according to the frequency method ${ }^{[6]}$ and compared with the design cable force, when the cable force value difference ratio is second cable adjustment is required outside the allowable range of the meter requirements. In order to facilitate construction and safety considerations, the actual cable adjustment is carried out on the main girder. The cable force of the cable far from the main tower is adjusted. At the same time, it has the greatest influence on the stress and deformation of the main tower and beam, so the cable far away from the main tower is first adjusted to reduce the total cable adjustment amount, so as to reduce the repeated deformation of the main girder caused by repeated cable $\operatorname{adjustment}^{[7]}$.

The basic idea of the influence matrix method is to obtain passive variables under the influence of the influence variables by adjusting the active variables. Among them, the active variable is the cable force change value that we need to adjust during construction, the influence variable is the core determining factor of the influence matrix, a cable force influence matrix is obtained through finite element software simulation, and the passive variable is the difference between the cable force value measured before we adjust the cable and the design cable force value.

\section{Case analysis}

\subsection{Project overview}

The project relied on in this paper is Linzhou Yingbin Bridge, the span of which is arranged as $4 \times 25 \mathrm{~m}$ prefabricated prestressed concrete bridge deck continuous small box girder $+(80+40) \mathrm{m}$-stayed bridge with double cable surfaces and single tower without back cables $+4 \times 25 \mathrm{~m}+3 \times 25 \mathrm{~m}$ prefabricated prestressed concrete bridge deck continuous small box girder, bridge width $25.5 \mathrm{~m}$. The main bridge adopts a detached bridge tower with an inclination of 59 and a tower height of $66.34 \mathrm{~m}$ above the bridge deck. The section of the tower column is rectangular and is of reinforced concrete structure. The stay cables are PE hot extruded cables with $\varphi 7$ parallel steel wire bundles, cold cast anchors, steel wire tensile strength standard value $1670 \mathrm{MPa}, 13$ pairs of stay cables are arranged in the main span, PES7-163 stay cables are adopted, and PES7-139 stay cables are adopted for C4-C13. C1 C3 The spacing of stay cables on the beam is $4 \mathrm{~m}$ and the spacing on the tower .Stretch at the beam end, with the tower end as the fixed end 3.414-$3.454 \mathrm{~m}$. The overall elevation layout of the main bridge is shown in the following Figure 1. 


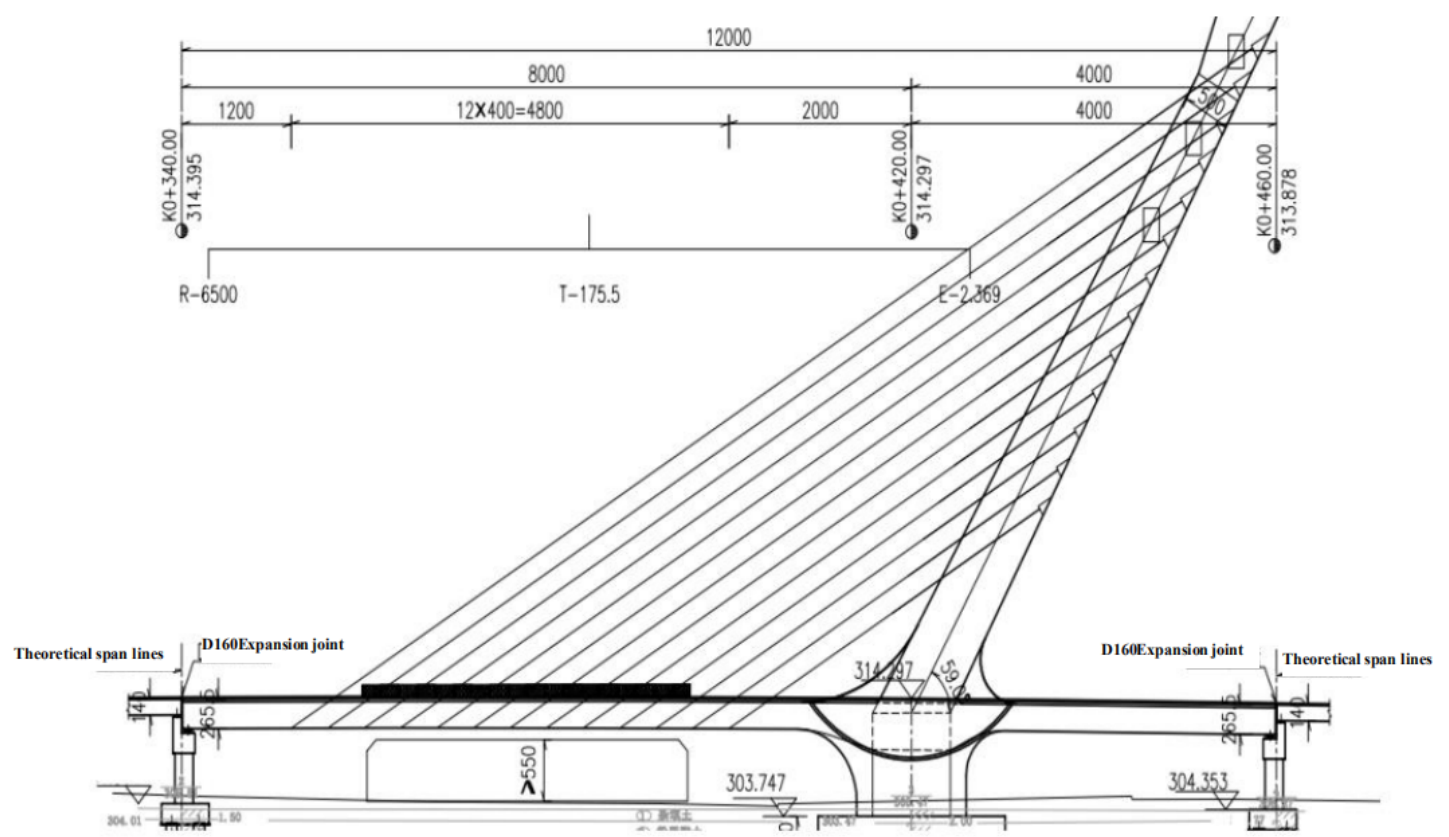

Figure 1. General arrangement diagram.

Using MIDAS /CIVIL and Finite Element Program to Establish Spatial Analysis Model of Main Bridge. Among them, the main tower, main girder and pier shaft are excavated. The beam element is used to simulate, and the cable is simulated by the tension-only truss element. The main boundary condition is that the connection of tower, beam and pier is elastic. Rigid connection simulation in connection, rigid connection in elastic connection between stay cable, main girder and main tower is used to simulate anchoring condition. The cross beam of the main tower and the main tower are connected in a common node to simulate the connection, the bottom of the pier shaft of the main pier is connected in a rigid way, and the two side piers are arranged according to the design. The design drawings are all hinged, and the finite element model is shown in the following Figure 2 and as shown in the following figure:

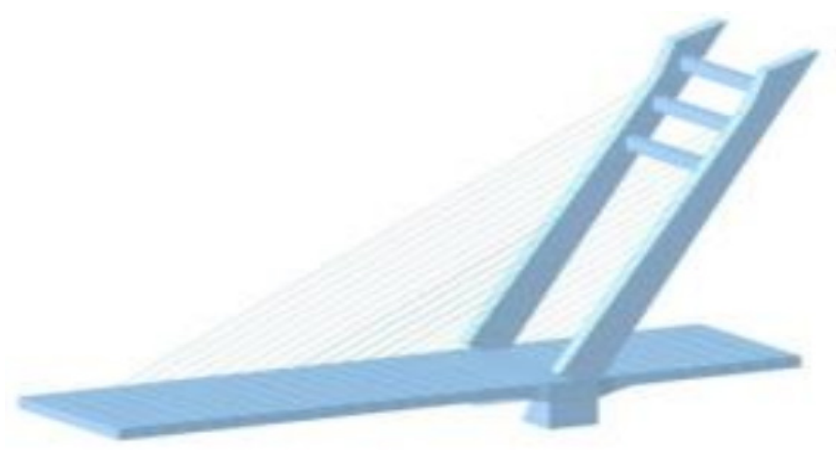

Figure 2. Finite element diagram

\subsection{Cable adjustment plan}

The comparison between the completed cable force and the designed cable force shows that the cable force difference of most cables after deck pavement is within the allowable range of the code.

According to the existing model, combined with the theory of influence matrix method, the unit cable force is applied to each stay cable in the model to calculate the cable force transformation values of other stay cables, and the influence matrix of stay cables of Yingbin Bridge is obtained by normalization principle ${ }^{[8]}$. The cable-stayed bridge without back cables is completely symmetrical in transverse direction, and the cable influence matrices on both sides are completely consistent.

According to formula and 5, the cable force value to be adjusted for each cable can be obtained by combining the difference between the measured cable force value and the designed cable force value. In order to reduce the difficulty 
and complexity of construction, only some cables are adjusted. Through calculation, it can be found that only the left cable is adjusted.

The cable forces of side cables, ZC7, right cables, YC13, YC11 and YC11 can control the cable forces of the whole bridge within the design error range, so only the cable forces of these three cables are adjusted. "According to the calculation, the cables on the left ZC7 can only relax part of the cable force to satisfy that all cables on the left are within 5\%. Therefore, the cables on the left ZC7 are only slightly adjusted, and the optimal adjustment value is $-70 \mathrm{KN}$. The right cables YC13 and YC11 are located at the bottom of the main tower, and their cable force values should be lower than the design cable force values as much as possible within the allowable range as a safety reserve for the damage of the main tower and cables far away from the main tower under the action of wind or earthquake. Therefore, in this adjustment, the difference between the measured cable force of the right cable and the design cable force is converted according to zero. The specific cable adjustment scheme is shown in Table 2 (negative value means the cable force is reduced). The comparison between the theoretical cable force after cable adjustment and the design cable force is shown in Figures 3 and 4. It can be seen that the cable adjustment scheme is feasible. The theoretical cable adjustment has certain influence on other cable forces, but it meets the expectation and the cable force difference is still within the allowable range.

\begin{tabular}{llcc}
\hline ZC7 & 1 & 3069.1 & -70 \\
YC13 & 2 & 2714.0 & -200 \\
YC11 & 3 & 2594.3 & -100 \\
\hline
\end{tabular}

Figure 3. Left amplitude theoretical cable force and design cable force comparison

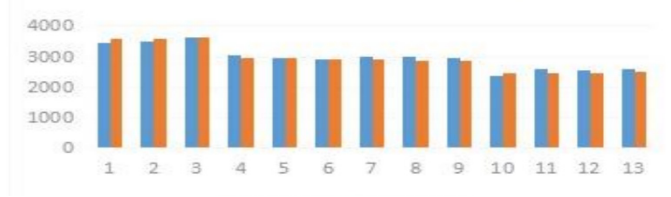

Figure 4. Right amplitude theoretical cable force and design cable force comparison

\subsection{Results analysis}

According to the cable force adjustment scheme, the cable force of the whole bridge is measured after the cable force adjustment, and the cable force is actually measured. The comparison results between the value and the design cable force are shown in Figure 5 and Figure 6.

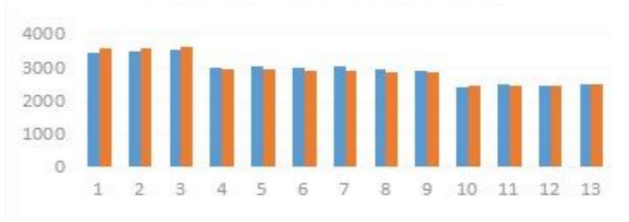

Figure 5. Left frame completed bridge cable force and design cable force contrast.

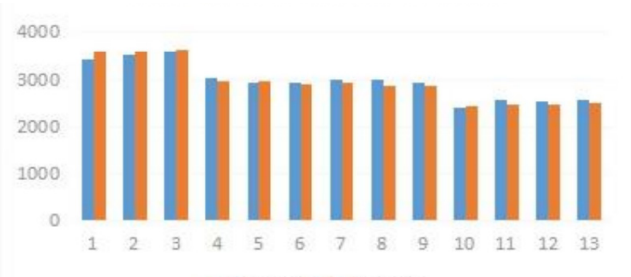

Figure 6. Right frame completed bridge cable force and design cable force contrast. 


\section{Conclusion}

Based on the cable adjustment analysis and practice of cable-stayed bridges without back cables, the following conclusions can be drawn:

(1.) The second cable adjustment analysis of cable-stayed bridges without back cables is carried out by using the influence matrix method. The method is simple, the theory is reliable and the cable is adjusted.

(2.). The workload is small. The error between the adjusted cable force and the target cable force is within 5\%, which meets the specification requirements. The cable adjustment within the range of has little effect on the overall cable tension value, and the cable tension change amplitude is relatively large except for the target. In addition to the stay cables, there are also two stay cables in the front and back of the target stay cables.

(3). During the construction of cable-stayed bridges without back cables, attention should be paid to the time period of cable force measurement, and the time period of measurement should be guaranteed as much as possible. Therefore, the influence of temperature on the cable force is avoided and the measurement error is reduced. It is suggested that the measurement time should be before sunrise in the morning, when the surface temperature and the design temperature difference is about $5^{\circ} \mathrm{C}$ and the measurement error is relatively small.

\section{References}

1. Cable-stayed Bridge without Backstays,[A] ,Lou Zhuanghong, Li Lingfu, Bridge and Structural Engineering Branch of China Highway Society ,2005 Proceedings of National Bridge Academic Conference, [C]. 2005

2. Xiang Xuxia, Jin En, Wesley Chan. Influence of Random Construction Errors of Stay Cables on Cable-Stayed Bridges [J]. Structural Engineers, 2011,27(01):154-160.

3. Pang Liancai. Analysis on the Influence of Prestressing Effect on Cable Tension Optimization of Cable-Stayed Bridge without Backstays [J]. Engineering and Construction, 2012,26(03):295-297.

4. Ren Zhigang, Liu Weijun, Du Xiaoyong, Xu Peng, Lu Zhean. Calculation Method of Secondary Cable Adjustment in Cable-stayed Bridge Construction Phase [J]. Bridge Construction, 2011(03):56-60.

5. Liuyong, Liu Jianfeng. Study on Determination of Extra Long Lasso Force Based on Vibration Characteristics [J]. Structural Engineer, 2009,25(06):117-122.

6. Wu Kangxiong, Liu Keming, Yang Jinxi. Cable Force Measurement System Based on Frequency Method [J]. China Journal of Highway And Transport, 2006(02):62-66.

7. Wang Yibing. Calculation and Test Research on Secondary Cable Adjustment of Cable-stayed Bridge [J]. Highway, 2016, 61(05):79-81.

8. Yang Xing, Zhang Min, Zhou Shuixing. Application of Influence Matrix Method in Secondary Cable Adjustment of Cable-Stayed Bridges [J]. Journal of Chongqing Jiaotong University (Natural Science Version), 2009,28(03):508511.

9. Wang Yibing. Calculation and Test Research on Secondary Cable Adjustment of Cable-stayed Bridge [J]. Highway, 2016,61(05):79-81.

10. Zhang Hongyue, Tian Shizhu. Method for improving the estimation accuracy of cable force of cable stayed [J]. Earthquake Engineering and Engineering Vibration, 2004(04):148-151. 